\title{
A new PDMS-b-PPO block copolymer membrane with novel non-perforated structure towards high flux for alcohol permselective pervaporation
}

\author{
W. Liu' ${ }^{1}$ H. X. Guo ${ }^{2,3^{*}}$, S. L. Ji ${ }^{1,3}$, H. J. Niu' ${ }^{1}, J . R . L i^{1,3}$ \\ ${ }^{1}$ College of Environmental and Energy Engineering, Beijing University of Technology, 100124 Beijing, PR China \\ ${ }^{2}$ College of Materials Science and Engineering, Beijing University of Technology, 100124 Beijing, PR China \\ ${ }^{3}$ Beijing Key Laboratory for Green Catalysis and Separation, 100124 Beijing, PR China
}

Received 11 August 2014; accepted in revised form 24 October 2014

\begin{abstract}
The effective permselective pervaporation of alcohol is one of key technology for bio-alcohol industrial production. In this work, a new polydimethylsiloxane-block-polyphenylene oxide (PDMS-b-PPO) copolymer was first synthesized by a bridge reagent technique. Based on the copolymer structure confirmation, the asymmetric PDMS-b-PPO membrane was subsequently prepared by phase-inversion method in order to improve the anti-swelling capacity of PDMS. SEM observation indicated that the morphology of as-prepared membrane exhibited a 'non-perforated' structure, resulting from the phase-inversion and micro-phase separation of the PDMS-b-PPO copolymer in the membrane forming process. Furthermore, the structure changes of the membranes with different ratio of PDMS to PPO were investigated. This non-perforated structure in the membrane favored to reduce the diffusion resistance, together with the affinity of PDMS segment to alcohol during pervaporation process. Thus, the prepared PDMS-b-PPO membrane showed dramatically increased flux, in pervaporation separation of alcohol/water mixture. The flux of the PDMS-b-PPO membrane (PDMS content of 42.4\%) can reach $3816.8 \mathrm{~g} /\left(\mathrm{m}^{2} \cdot \mathrm{h}\right)$, along with 8.53 of separation factor in pervaporation of $5 \mathrm{wt} \%$ alcohol/water mixture $\left(60^{\circ} \mathrm{C}\right)$. This work may provide a new strategy to design and fabricate new copolymer membranes for improving alcohol permselective pervaporation.
\end{abstract}

Keywords: polymer membranes, alcohol permselective pervaporation, block copolymers, non-perforated structured membrane

\section{Introduction}

Bio-alcohol has been promoted as a benign environmental source to solve energy problem worldwide [1-4]. The coupling of pervaporation (PV) and fermentation for bio-alcohol production has received increasing attention because the produced bio-alcohol can be timely in-situ recovered from fermentation using pervaporation technology $[5,6]$, so that the inhibition of fermentation from high alcohol concentration can be effectively reduced. Thus, the alcohol permselective pervaporation membrane with higher separation efficiency is one of the most important keys to accomplish the coupling of PV and fermentation.

Polydimethylsiloxane (PDMS) is one of the most representative membrane materials for pervaporation recovery of alcohols from their aqueous solutions, due to the advantages, such as high thermo-stability, hydrophobicity, low-surface tension, biocompatibility, and commercial availability. However, the wide utilization of PDMS is limited for its low glass transition temperature, difficult membrane-forming property, and poor cohesion, which lead to PDMS membrane cumbersome curing and lower anti-swelling

\footnotetext{
${ }^{*}$ Corresponding author, e-mail: hxguo@bjut.edu.cn

(C) BME-PT
} 
[7-13]. A few of modifications on PDMS have been made to improve these deficiencies, such as crosslinking, filling, graft, and block copolymerization [14-19], of which graft or block copolymerization offered an appealing route to generate new types of materials that combine the superior properties of multiple polymers. For example, Dong et al. [15] prepared poly(1-phenyl-1-propyne) (PPP)/PDMS graft copolymer membranes, in order to improve the anti-swelling capacity of PDMS. This PPP/PDMS membrane showed excellent permselectivity towards alcohol, acetone, dioxane, acetonitrile, and pyridine by pervaporation separation, due to that the rigid PPP chains of PPP/PDMS endowed the membrane a good anti-swelling capacity. Jiang et al. [20] has investigated a new kind of fluoridated siloxaneimide block copolymer (PSI) membrane for organicpervaporation. This fluoridated imide blocks in the PSI improved the mechanical strength of the PDMS membranes without reducing its separation factors. Moreover, the similar modification of PDMS were carried out to synthesize polydimethylsiloxaneblock-polymethylmethacrylate copolymer [21], polydimethylsiloxane-graft-polymethylmethacrylate copolymer [22], and polydimethylsiloxane/polystyrene interpenetrating polymer network [23]. All these works demonstrated that the poor properties of PDMS can be effectively improved by graft or block copolymerization with other relatively rigid polymers.

Polyphenylene oxide (PPO) is a thermoplastic polymer, which shows excellent chemical and thermal stability, and has been widely applied in pervaporation separation. For example, the asymmetric PPO membrane, prepared by Schauer et al. [24], has been applied in pervaporation separation of alcohol/water, which can permeate alcohol, preferentially. Herein, we regarded the rigid PPO polymer as a good candidate to combine with PDMS through graft or block copolymerization. Our previous work has fabricated a novel PDMS/bromide-substituted PPO (BPPO) membrane by in situ crosslinking method [25]. The results showed that existence of PPO really improved the anti-swelling capacity of PDMS, and the resultant PDMS/BPPO membrane exhibited a high selectivity towards butanol. However, the flux of such PDMS/BPPO membrane was not satisfactory due to its densely crosslinked structure. Therefore, to further improve flux of the membrane, this work synthesized a series of polydimethylsiloxane- block-polyphenylene oxide copolymers (PDMS-bPPO) by reactive crosslinking method, using 2, 4diisocyanatotoluene (TDI) as crosslinking reagent. Then, the asymmetric PDMS-b-PPO membranes were prepared by phase-inversion method. The morphologies and constituent of the membrane with tunable ratio of PDMS to PPO were investigated. The SEM results showed that the PDMS-b-PPO membrane presented a network porous structure both on the surfaces and in the cross-section, while the permeation and pervaporation tests showed that this porous membrane exhibited a 'non-perforated' structure (porous but the pores were not truly through holes). This novel 'non-perforated' structure led to a high flux in alcohol permselective pervaporation. This work may provide a new way to design and prepare asymmetric membrane with improved pervaporation performance, efficiently.

\section{Experimentals}

\subsection{Materials}

PDMS (KF-8008, average molecular weight of $11400 \mathrm{~g} / \mathrm{mol}$, dual-terminated with aminopropyl group), was purchased from Japan's Shin-Etsu Chemical Industry Company. PPO (average molecular weight of $16000 \mathrm{~g} / \mathrm{mol}$ ) was purchased from Hao Di Chemical Trading Company (Kun Shan, China). 2,4-diisocyanatotoluene (TDI), dibutyltin dilaurate (DBTDL), and chlorobenzene were supplied by Tianjin Fuchen Chemical Reagents Company (Tianjin, China). Analytically grade chlorobenzene, chloroform, methanol, alcohol, 2-propanol, and butanol were purchased from Beijing Chemical Company (Beijing, China).

\subsection{Synthesis of \\ polydimethylsiloxane-block-polyphenylene oxide copolymers (PDMS-b-PPO)}

Calculated amount of PDMS, PPO and TDI were dissolved in chlorobenzene under stirring to obtain $10 \mathrm{wt} \%$ solutions, respectively. TDI solution was firstly transferred into a dried $500 \mathrm{~mL}$ flask. When the temperature of the flask was elevated at $80^{\circ} \mathrm{C}$, the PPO solution was dropwise added into TDI solution under vigorous stirring and nitrogen atmosphere. Then, the PDMS solution together with $3 \mathrm{~mL}$ of DBTDL was added into the flask reactor. The temperature of the reaction system was elevated to $130^{\circ} \mathrm{C}$ and kept for $3 \mathrm{~h}$. At last, the insoluble solids produced after cooled down to ambient temperature. The prod- 
uct was filtrated and washed with methanol thoroughly, and the powder-like PDMS-b-PPO copolymers were collected and dried in a vacuum oven at $50^{\circ} \mathrm{C}$ for $48 \mathrm{~h}$.

\subsection{Preparation of PDMS-b-PPO membrane}

The asymmetric PDMS-b-PPO membranes were prepared by phase inversion method. Typically, precalculated amount of PDMS-b-PPO and n-butyl alcohol was firstly dissolved in chloroform solvent to form a casting solution. The casting solution was spread on a level glass shutter by Gardner knife under ambient atmosphere. Then the glass shutter was immersed into a methanol coagulation bath. The asobtained asymmetric PDMS-b-PPO membrane was peeled off and dried in a vacuum oven for $24 \mathrm{~h}$.

\subsection{Characterizations}

The prepared PDMS-b-PPO copolymers were characterized by FTIR (Nicolet, 5DX instrument) and ${ }^{1} \mathrm{H}-\mathrm{NMR}$ analysis (Avance 400M, Bruker, Germany). The content of PDMS was calculated by the area ratio of the characteristic elements (mass fraction was equal to the product of the unit molecular weight and unit mole ratio. In this work, the area ratio is the unit mole ratio). The morphologies of membranes were characterized by SEM (Hitachi S-4300, Japan).

\subsection{Pervaporation experiments}

The pervaporation apparatus in this work is presented in Figure 1. The membrane was installed in a glass pervaporation cell with an operational area of $28 \mathrm{~cm}^{2}$. The feed was circulated through the pervaporation cell by a peristaltic pump. The downstream pressure was kept at approximately $0.1 \mathrm{kPa}$ by a vac-

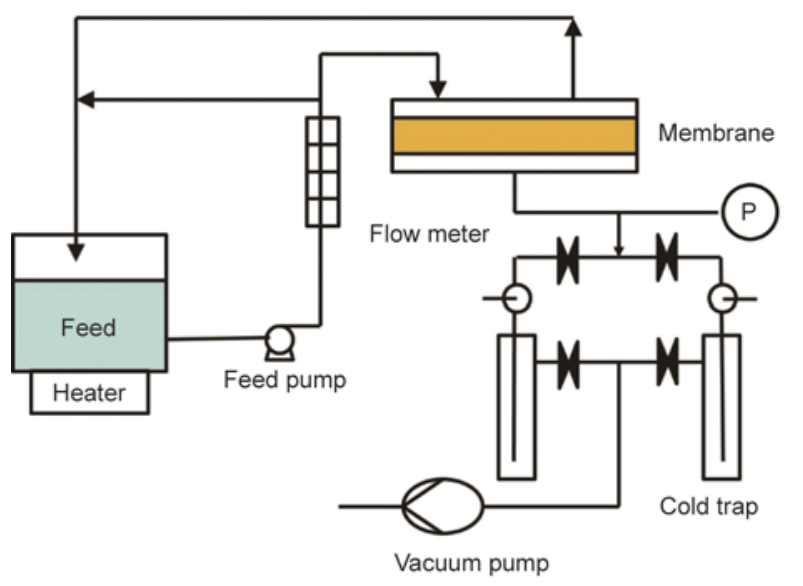

Figure 1. Scheme of experimental apparatus for pervaporation uum pump. Permeate was collected through the condensation by liquid nitrogen. All the feeds are alco$\mathrm{hol} /$ water mixture with a ratio of 1:20 (5 wt \% of the alcohol), and the operating temperature is $60^{\circ} \mathrm{C}$. The feed and permeate compositions were analyzed by gas chromatography (GC7900, Tianmei Corporation, Shanghai, China), where the operating temperatures were $160^{\circ} \mathrm{C}$ in injector, $150^{\circ} \mathrm{C}$ in column and $160^{\circ} \mathrm{C}$ in detector. The separation factor was calculated from the quotient of the weight ratio of alcohol and water in the permeate, $Y_{\text {alcohol }} / Y_{\text {water, }}$ and in the feed, $X_{\text {alcohol }} X_{\text {water }}$ is given by Equation (1):

$\alpha=\frac{\frac{Y_{\text {alcohol }}}{Y_{\text {water }}}}{\frac{X_{\text {alcohol }}}{X_{\text {water }}}}$

The flux $(J)$ was calculated through weight of permeate $(W)$ at unit time $(t)$ and unit area $(A)$ by Equation (2):

$J=\frac{W}{t \cdot A}\left[\mathrm{~g} \cdot \mathrm{m}^{-2} \cdot \mathrm{h}^{-1}\right]$

\subsection{Permeation experiment}

Permeation experiments were used to prove the "nonperforated' structure in the PDMS-b-PPO asymmetric membranes. The permeation test of PDMSb-PPO membrane was conducted with an effective area of $26 \mathrm{~cm}^{2}$. Deionized water and alcohol were used as the feeds. The experiments were carried out at a pressure of $0.6 \mathrm{MPa}$ produced by a plunger pump. Permeations flux $(F)$ were determined by measuring the volume of liquid collected over a measured time under steady-state conditions. $F$ was calculated as shown by Equation (3):

$F=\frac{V}{t \cdot A}\left[\mathrm{~mL} \cdot \mathrm{m}^{-2} \cdot \mathrm{h}^{-1}\right]$

where ' $V$ ' is the permeate volume $[\mathrm{mL}]$, ' $t$ ' stands for the time [hours], and ' $A$ ' denote the effective membrane surface area $\left[\mathrm{m}^{2}\right]$.

\section{Results and discussion}

\subsection{Synthesis and structures of PDMS-b-PPO copolymer}

As illustrated in Figure 2, PDMS-b-PPO was synthesized by the reaction of the isocyano $(-\mathrm{NCO})$ of TDI with aminopropyl $\left(-\mathrm{CH}_{2} \mathrm{CH}_{2} \mathrm{CH}_{2} \mathrm{NH}_{2}\right)$ groups 


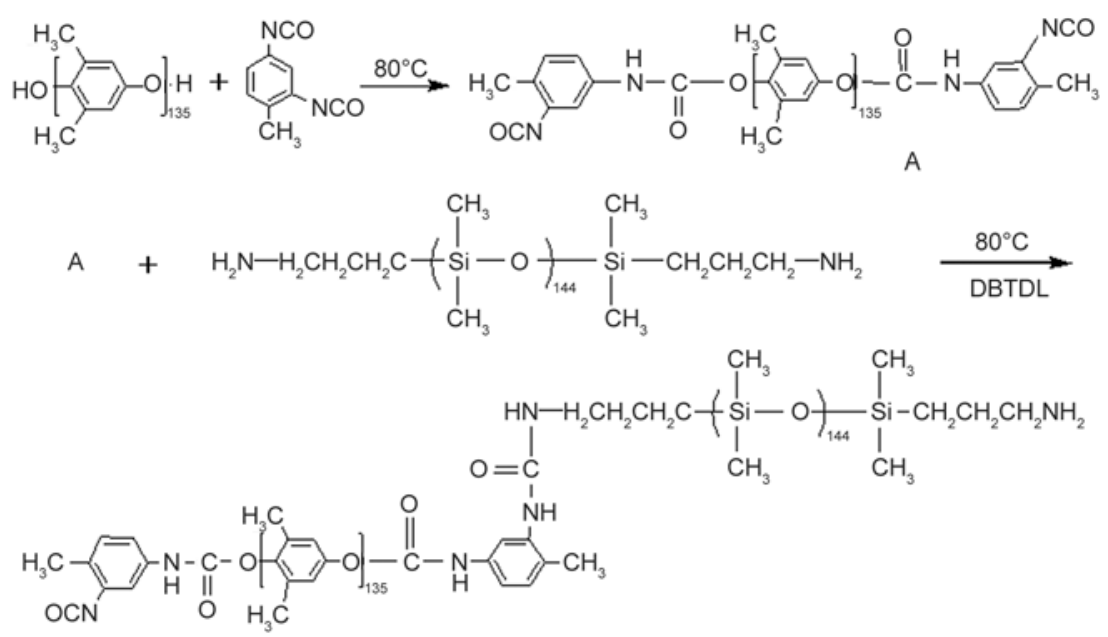

Figure 2. The reaction scheme of the formation of PDMS-b-PPO copolymer

of PDMS and hydroxyl (-OH) groups of PPO to form urethane and substituted urea group, respectively. The synthesis process was controlled by two stages. In the first stage, the reaction system was controlled at temperature of $80^{\circ} \mathrm{C}$ for one of isocyano $(-\mathrm{NCO})$ of TDI to react with hydroxyl $(-\mathrm{OH})$ group of PPO to form urethane, as well as in order to inhibit the self-polymerization of TDI. After the introduction of PDMS and dibutyltin dilaurate (DBTDL) solution, the other isocyano (-NCO) of TDI would be attacked by the aminopropyl group of PDMS in presence of dibutyltin dilaurate (DBTDL) other than $-\mathrm{OH}$ group of $\mathrm{PPO}$ because of the steric hindrance. Thus, the initial PDMS-b-PPO copolymer segments were formed. For the second stage, the temperature was further elevated and kept for $3 \mathrm{hrs}$. in order to complete the reaction.

To evidence of the formation of the PDMS-b-PPO copolymer, the FTIR spectra of PDMS, PPO, TDI, and PDMS-b-PPO were illustrated as in Figure 3. The PDMS spectrum in Figure 3 indicated typically the $\mathrm{Si}-\mathrm{O}-\mathrm{Si}$ stretching peak, $\mathrm{CH}_{3}$ bending peak, $\mathrm{CH}_{3}$ rocking peak, and $\mathrm{C}-\mathrm{H}$ stretching peak appeared at 1100-1000, 1260, 797.35, and $2989 \mathrm{~cm}^{-1}$, respectively. The spectra of PPO showed the benzene ring peak, $\mathrm{C}-\mathrm{O}$ stretching peak, and $\mathrm{CH}_{3}$ rocking peak appeared at 1468, 1306, and $857 \mathrm{~cm}^{-1}$, respectively. And the peak at $2261 \mathrm{~cm}^{-1}$ clearly indicated $-\mathrm{N}=\mathrm{C}=\mathrm{O}$ of TDI. In contrast, the characteristic peaks of PDMS and PPO are presented in the spectrum of PDMS-b-PPO copolymer. Meanwhile, the characteristic peak of TDI disappeared and a new peak appeared at $1711.9 \mathrm{~cm}^{-1}$, which was ascribed to the produced urethane group. These results indicated that the PDMS-b-PPO was really formed.

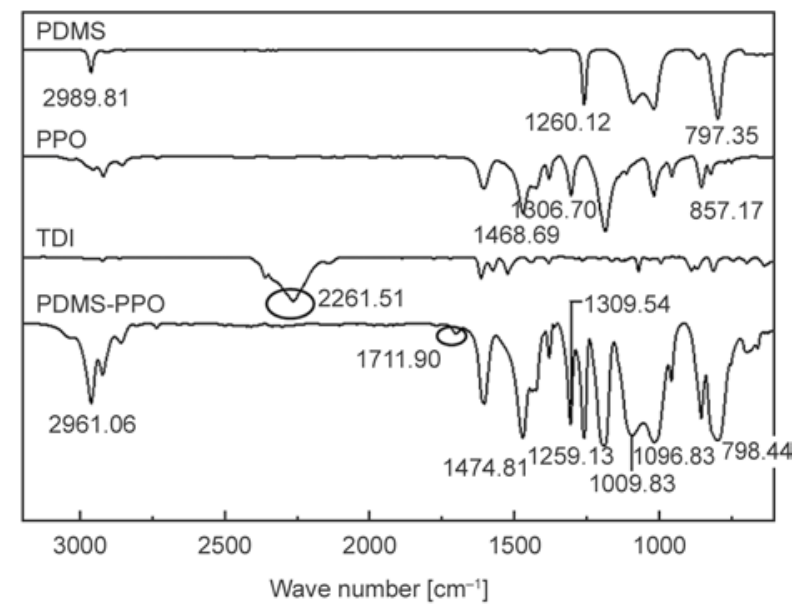

Figure 3. FTIR spectra of PDMS, PPO, TDI and PDMS-bPPO copolymers

The typical ${ }^{1} \mathrm{H}-\mathrm{NMR}$ spectrum of the PDMS-bPPO copolymers was shown in Figure 4. The peak at 7.256 ppm of Figure 4 was ascribed to the characteristic peak of deuterated chloroform solvent.

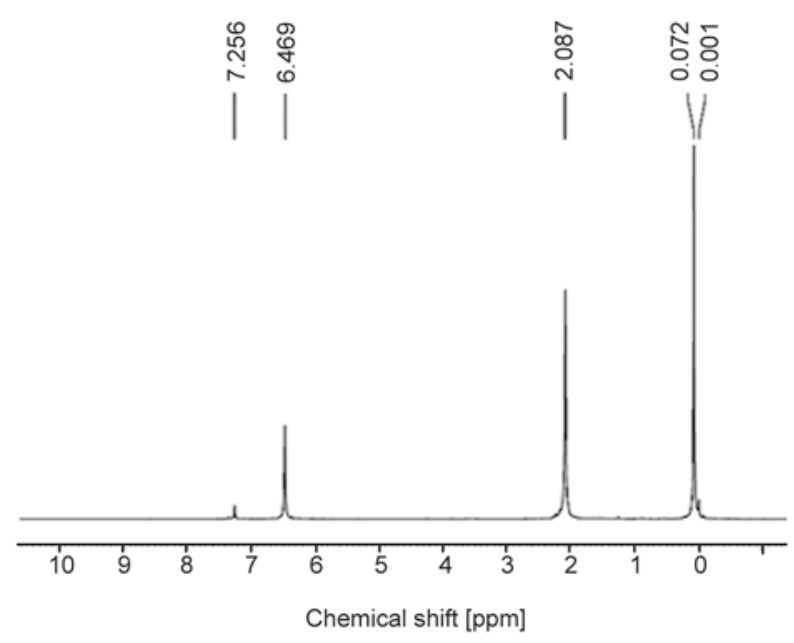

Figure 4. ${ }^{1} \mathrm{H}-\mathrm{NMR}$ spectra of PDMS-b-PPO copolymer 
And the two peaks at 6.469 and $2.087 \mathrm{ppm}$ were ascribed to the proton of aromatic and methyl group of PPO, respectively, and the peak at $0.072 \mathrm{ppm}$ was attributed to the proton of siloxane. The area ratio of the three signals at $6.469,2.087$ and $0.072 \mathrm{ppm}$ was used to calculate the PDMS content.

\subsection{The morphologies of as-prepared PDMS-b-PPO membrane}

Generally, PDMS cannot be directly formed into an asymmetric membrane by phase-inversion method because of its poor mechanical property. However, our PDMS-b-PPO copolymer can form a wholly continuous non-substrate membrane by phase-inversion method, due to existence of more rigid PPO segments. As shown in Figure 5, the surface and cross-section morphologies of the membranes indicated that the surface morphology of PPO asymmetric membrane (Figure 5a) was very dense and com-

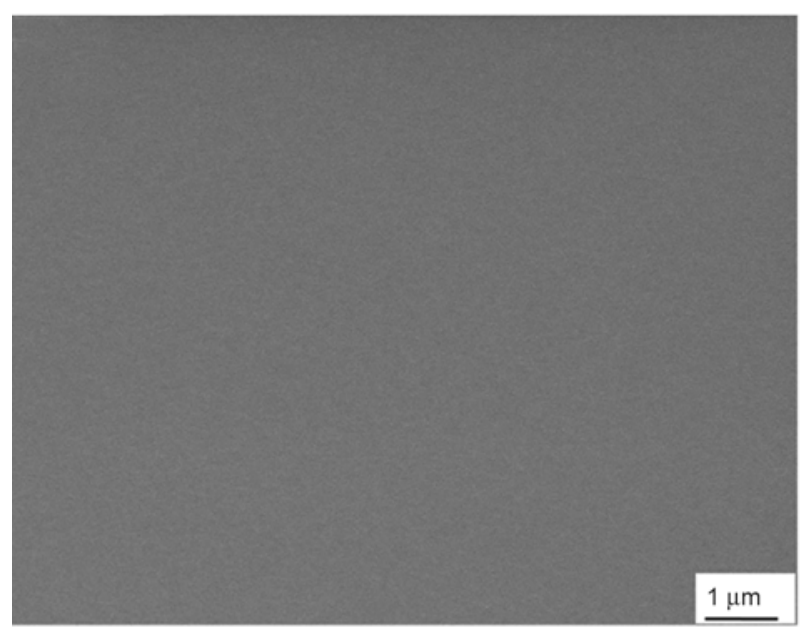

a)

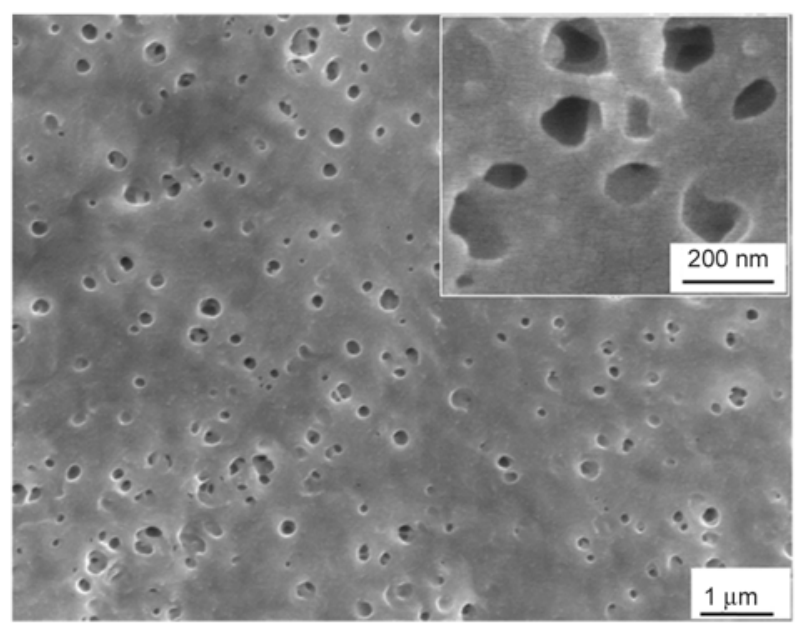

c) pact, and its cross-section (Figure 5b) exhibited a typical pear-shaped finger-like structure. In contrast, the surface of our PDMS-b-PPO membrane (prepared by the ratio of PDMS:PPO:TDI was $1.5: 1: 2$ ) was porous-like (Figure 5c) with pore size of about $100 \mathrm{~nm}$. But the enlarged image in the inset of Figure $5 \mathrm{c}$ indicated that the surface displayed much non-perforated pores. And the image of the cross-section (Figure 5d) showed a sponge-like network structure with pore size about $0.5-1.0 \mu \mathrm{m}$. The formed novel morphology of the PDMS-b-PPO membrane was mainly resulted from the specific hard and soft segments of the copolymers and the membraneforming processes; that is, the microphase separation of the block copolymers and the phase-inversion process. As illustrated in Figure 6, when the casting solution consisting of PDMS-b-PPO dissolved in n-butyl alcohol and chloroform was spread onto a glass shutter and then immersed into methanol

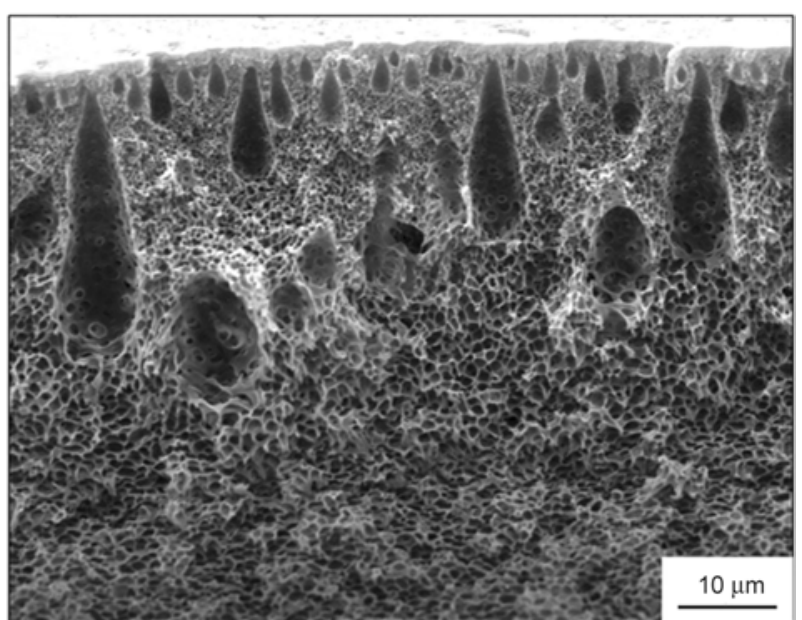

b)

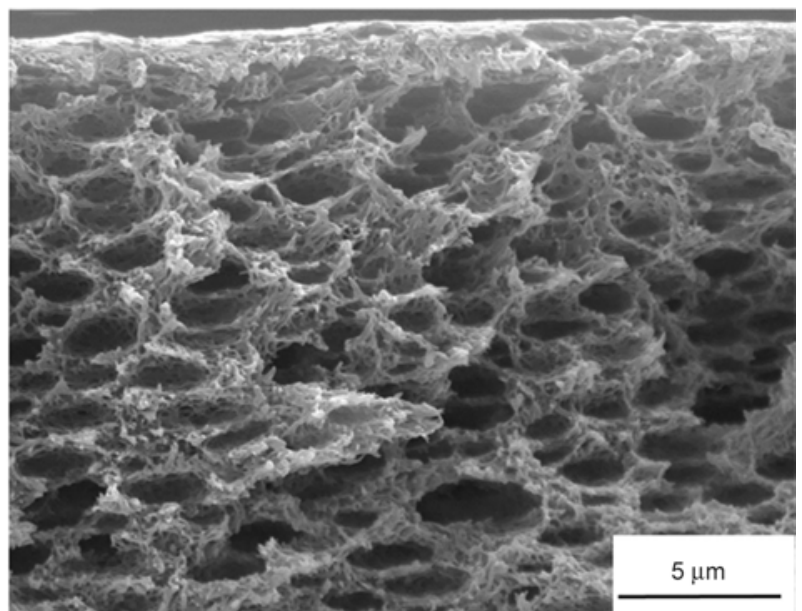

d)

Figure 5. The SEM of the surface and the cross-section of PDMS-b-PPO membrane. a) surface of PPO asymmetric membrane; b) cross-section of PPO asymmetric membrane; c) surface of PDMS-b-PPO membrane; d) cross-section of PDMS-b-PPO membrane (PDMS:PPO:TDI =1.5:1:2). 


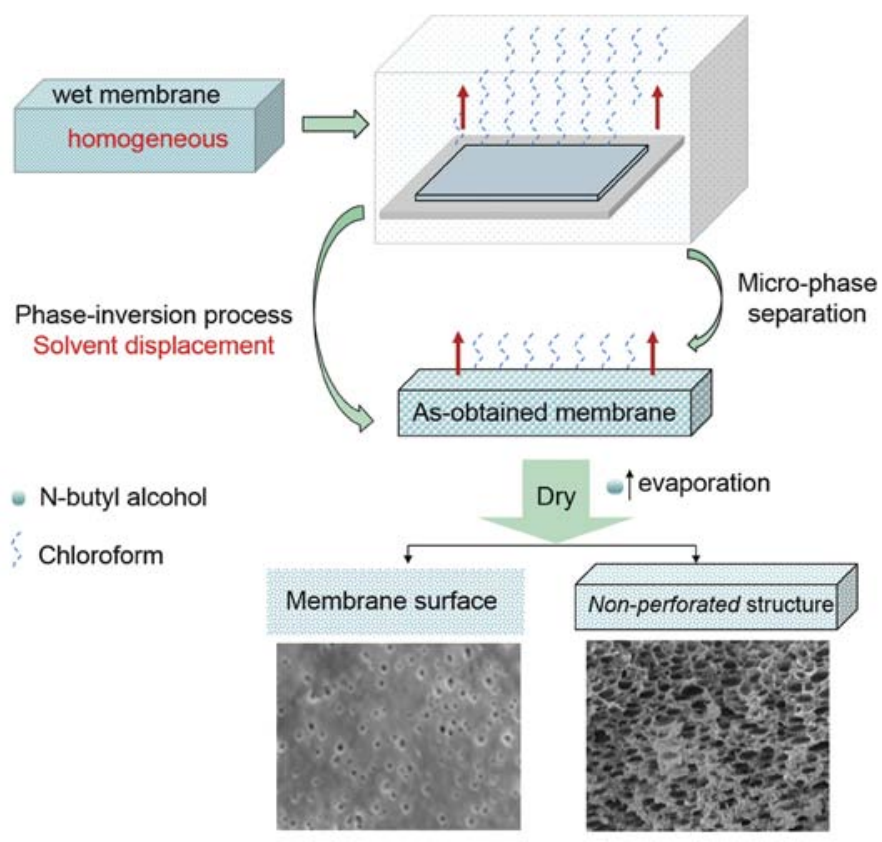

Figure 6. Phase-inversion process of PDMS-b-PPO membrane

coagulation bath, the phase inversion occurred. The solvent displacement between liquid component and gel proceed due to the existence of poor and rich phase region in the PDMS-b-PPO membrane, resulting in the porous structure. Furthermore, during membrane forming process, the solvent of n-butyl alcohol could be partially displaced by methanol when immersed into methanol coagulation bath, due to the compatibility between PDMS and n-butyl alcohol. Thus, the cross section of the PDMS-b-PPO membrane appeared as sponge-like other than finger-like structure. Moreover, when the phase inversion finished, the PDMS domains in outer skin layer of PDMS-b-PPO were swollen by methanol and nbutyl alcohol. And these wrapped solvents evaporated during drying, resulting in the shrinkage of PDMS segment and occurrence of subsidence areas, much similar to the porous-like but non-perforated structure. Simultaneously, the micro-phase separation of the as-prepared PDMS-b-PPO, resulting from the soft PDMS segment and the rigid PPO chain, caused that PDMS micro-region was uniformly dispersed in the PPO matrix to form such porous-like structure. The component of this micro-region can be further demonstrated by EDS shown in Figure 7. The blue points of Si element and the red points of $\mathrm{C}$ element in Figure 7 obviously indicated that the PDMS component in the blue Si domains was uniformly dispersed in the PPO matrix.

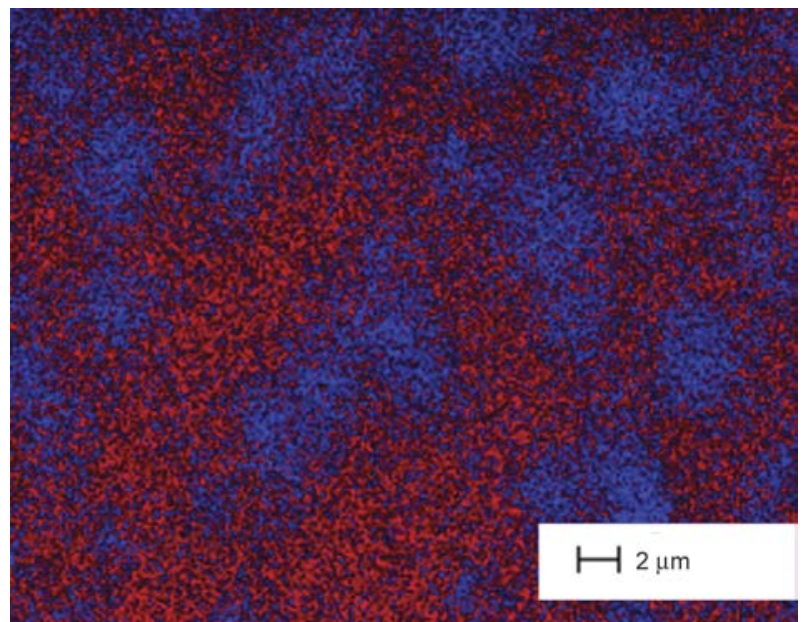

Figure 7. EDS scanning image of the PDMS-b-PPO membrane (blue points standardized Si element and the red points standardized C element)

To further demonstrate the porous-like but non-perforated structure of the surface and the cross-section of PDMS-b-PPO membrane, the permeation of aqueous solution was performed. Both of PPO and the PDMS-b-PPO asymmetric membrane were prepared by the phase-inversion method under the same conditions. The results in Figure 8 indicated that the pores in Figure $5 \mathrm{~b}$ and $5 \mathrm{~d}$ were not truly through holes, and really exhibited a non-perforated structure. When the feed liquid was water, the permeations of PPO and PDMS-b-PPO membrane were 3.0 and $15.0 \mathrm{~mL} /\left(\mathrm{m}^{2} \cdot \mathrm{h}\right)$ under $0.6 \mathrm{MPa}$, respectively. 


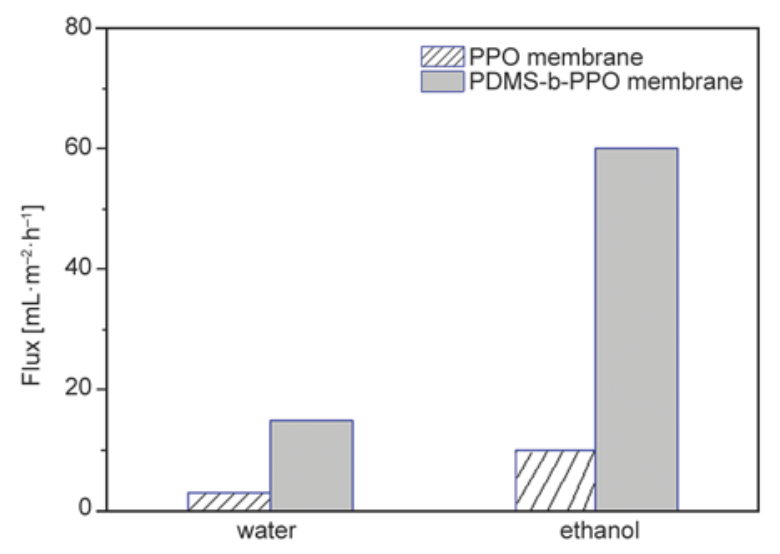

Figure 8. Permeation results of PPO membrane and PDMS-b-PPO membrane

The low permeation of pure water under relatively higher pressure demonstrated that the PPO membrane and PDMS-b-PPO membrane were dense and the water was difficult to permeate through. However, when the feed liquid was changed into alcohol, the permeation of the PPO membrane and PDMSb-PPO membrane were increased to 10.0 and $60 \mathrm{~mL} /\left(\mathrm{m}^{2} \cdot \mathrm{h}\right)$ under the same pressure, respectively. This was due to the better affinity between PDMS and alcohol. And the PDMS-b-PPO membrane showed a relatively higher permeation for alcohol. Thus, we can deduce that the porous structure of the PDMS-b-PPO membrane in Figure 5 was really non-perforated.

\subsection{The effect of raw material ratio on the structure of PDMS-b-PPO membranes}

To investigate the effect of the soft and rigid segment in PDMS-b-PPO copolymers on the structure of the membrane, series of PDMS-b-PPO copolymers with different constituents were prepared by different ratio of PDMS to PPO. The PDMS content in the PDMS-b-PPO copolymer was measured using ${ }^{1} \mathrm{H}-\mathrm{NMR}$ area ratio as shown in Table 1 . The results of Table 1 indicated that the PDMS content was some close to the theoretical ones. The relatively low

Table 1. The variation of PDMS content in the copolymers with different ratio of PDMS to PPO

\begin{tabular}{|c|c|c|c|}
\hline \multirow{2}{*}{ Sample } & \multirow{2}{*}{$\begin{array}{c}\text { PDMS:PPO:TDI } \\
\text { (mole ratio) }\end{array}$} & \multicolumn{2}{|c|}{$\begin{array}{c}\text { PDMS } \\
\text { [wt\%] }\end{array}$} \\
\cline { 3 - 4 } & & Theoretically added & Measured \\
\hline 1 & $0.5: 1: 2$ & 26.27 & 24.14 \\
\hline 2 & $1: 1: 2$ & 41.61 & 37.02 \\
\hline 3 & $1.5: 1: 2$ & 51.66 & 42.40 \\
\hline 4 & $1: 1: 3$ & 41.61 & 32.38 \\
\hline 5 & $1: 1: 4$ & 41.61 & 30.75 \\
\hline
\end{tabular}

PDMS contents in sample 3, 4, 5 of Table 1 may be probably due to that the excessive amount of TDI brought about the crosslinking structure, of which the long molecular chains increased the measurement error. Moreover, the content of PDMS in the copolymer increased with increasing the ratio of PDMS to $\mathrm{PPO}$, indicating that the composition of soft PDMS segments and rigid PPO segments in PDMS-b-PPO copolymers could be effectively tuned by the ratio of PDMS to PPO.

The morphologies of PDMS-b-PPO membrane with different ratio of PDMS to PPO on were investigated by SEM. As shown in Figure 9, all the PDMS-bPPO membranes exhibited 'non-perforated' porouslike structure. When the ratio of PDMS:PPO:TDI changed from $0.5: 1: 2$ to $1.5: 1: 2$, the PDMS content in PDMS-b-PPO increasing from 24.14 to $42.40 \mathrm{wt} \%$, and the corresponding images shown in Figure 9A, 9B, and 9C, indicated that the irregular and small pores existed in the surface and cross-section of membrane with the ratio of PDMS:PPO:TDI as 0.5:1:2, due to the low amount of soft PDMS segment in the copolymer. When the soft PDMS segment of the copolymer chains increased, the pores in the surface and the cross-section of membrane became relatively lager (Figure 9B and Figure 9C), resulting from that the increased PDMS brought about higher degree of microphase separation. Moreover, when the ratio of PDMS:PPO:TDI changed from 1:1:2 to 1:1:4 as shown in Figure 9B, 9D, and 9E, the surface and cross-section of the PDMS-b-PPO membrane became denser and even compact (Figure 9D-s). This was attributed to that the excessive amount of TDI may produce some crosslinking structure in the membrane and resulted in the restricted micro-phase separation process during formation of membrane. Therefore, the results in Figure 9 indicated that the morphology of such 'non-perforated' PDMS-b-PPO membrane can be tuned by changing the ratio of soft PDMS and rigid PPO.

\subsection{Pervaporation separation of the alcohol/water binary mixtures}

Figure 10 showed the effect of TDI amount on the pervaporation performances in the separation of alcohol/water, 2-propanol/water, and t-butanol/water mixtures. It can be noted that the separation factor and flux PDMS-b-PPO membrane decreasing with the increased of TDI amount. This was in accordance with the gradually denser and more compact 

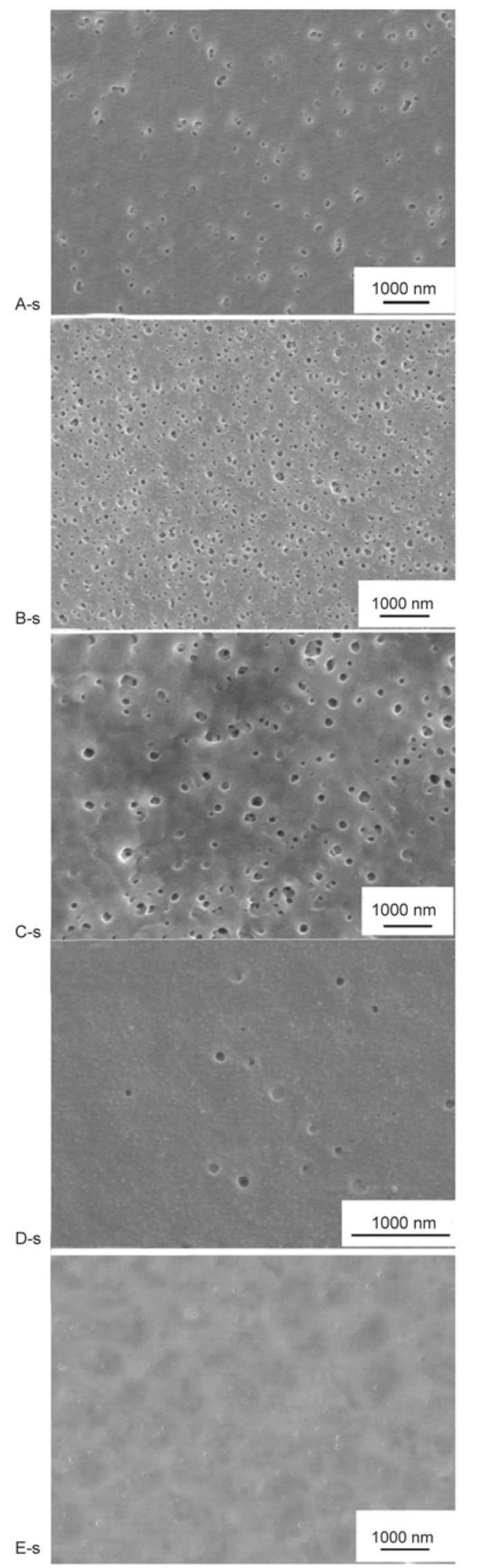
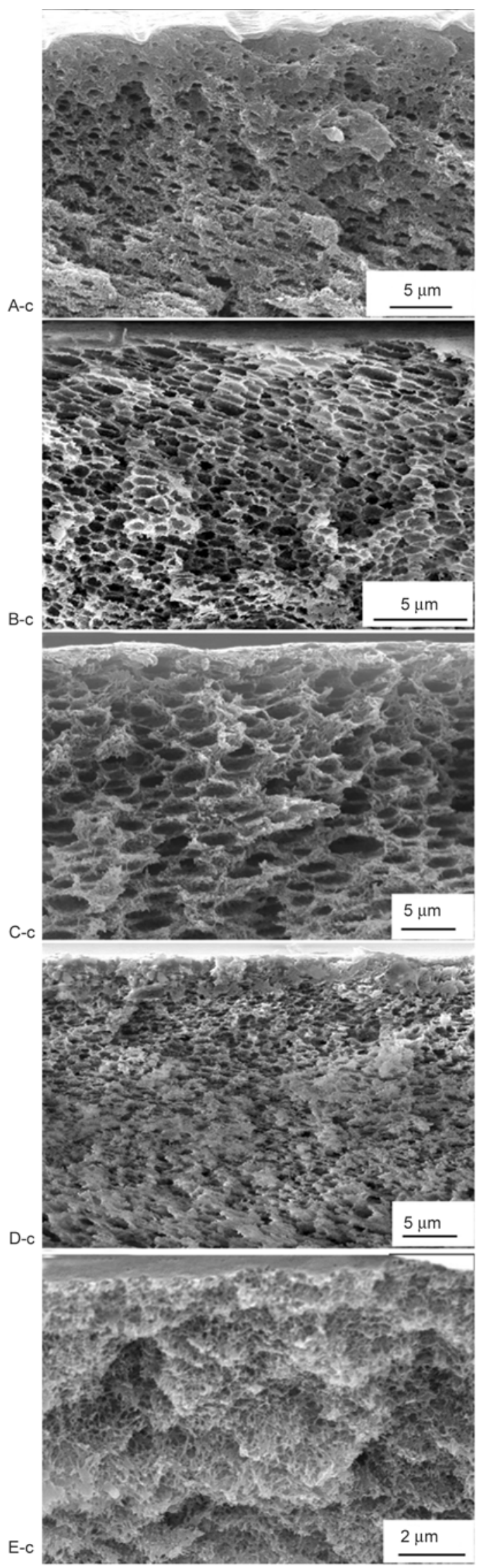

Figure 9. The SEM images of the membranes with different ratios of PDMS: PPO: TDI. ' $s$ ' represent the surface and ' $c$ ' represent cross-section. (A) PDMS:PPO:TDI=0.5:1:2 polymer membrane, (B) PDMS:PPO:TDI=1:1:2 polymer membrane, (C) PDMS:PPO:TDI = 1.5:1:2 polymer membrane, (D) PDMS:PPO:TDI=1:1:3 polymer membrane, (E) PDMS:PPO:TDI =1:1:4 polymer membrane. 


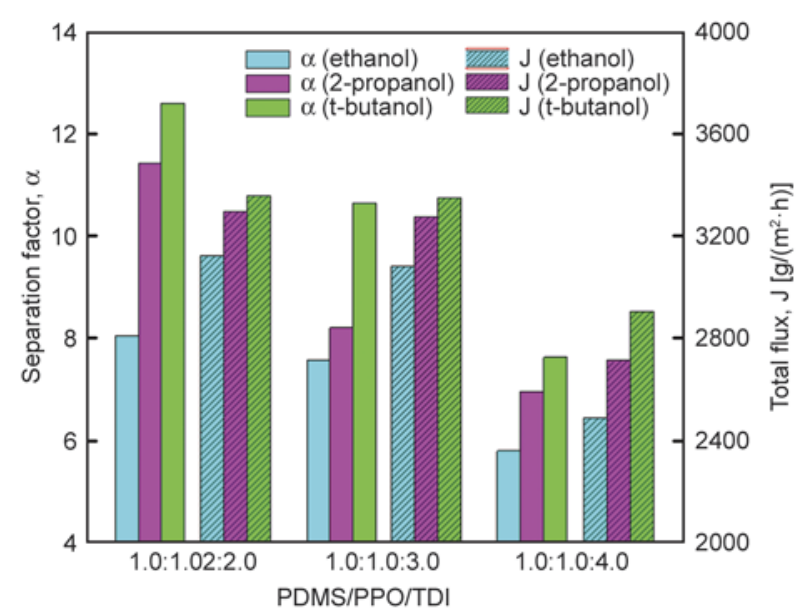

Figure 10. The effect of TDI amount on the pervaporation performances in the separation of alcohol/water, 2-propanol/water, and t-butanol/water mixtures

structure of Figure 9B, 9D, and 9E. Moreover, based on the results of Table 1, more usage of TDI resulted in some crosslinked PDMS-b-PPO. The microphase separation process of PDMS-b-PPO was then restricted, and the shrinkage of PDMS segment caused the surface and the cross-section became less porous and relatively compact. Thus, the separation factor and flux of PDMS-b-PPO membrane decreased. When the ratio of PDMS: PPO: TDI was $1: 1: 2$ (PDMS content is $37.02 \%$ ), the prepared membrane exhibited an optimum pervaporation performance. The separation factor $(\alpha)$ and flux $(J)$ were 8.06 and $3150.7 \mathrm{~g} /\left(\mathrm{m}^{2} \cdot \mathrm{h}\right)$ for alcohol/water mixture, 11.35 and $3390.8 \mathrm{~g} /\left(\mathrm{m}^{2} \cdot \mathrm{h}\right)$ for 2-propanol/ water and 12.7 and $33456.1 \mathrm{~g} /\left(\mathrm{m}^{2} \cdot \mathrm{h}\right)$ for t-butanol/ water mixture, respectively, with $5 \mathrm{wt} \%$ of the feed concentration and at $60^{\circ} \mathrm{C}$ of operation temperature. Figure 11 showed the effect of PDMS content in PDMS-b-PPO on pervaporation performances in

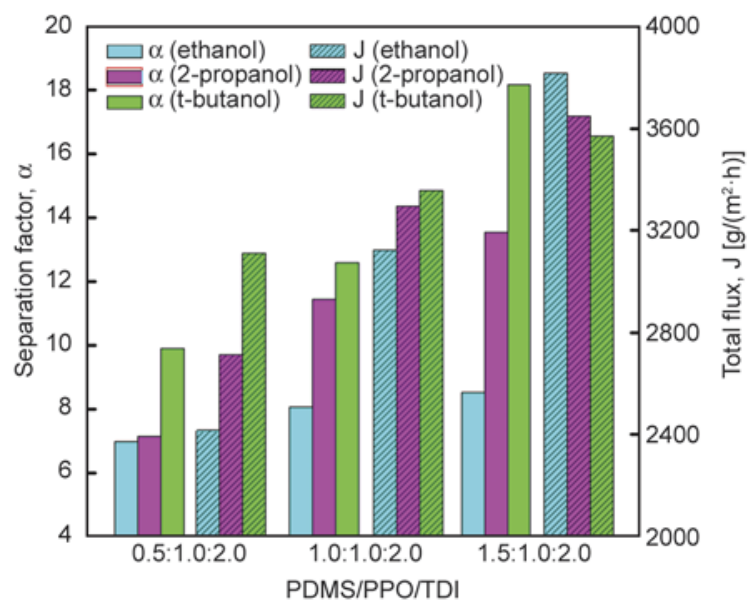

Figure 11. The effect of PDMS content in PDMS-b-PPO on pervaporation performances

the separation of alcohol/water, 2-propanol/water and t-butanol/water mixtures. It was noted that the separation factor and flux PDMS-b-PPO membrane increased with increasing of PDMS content, which was also in accordance with the variation of morphologies of Figure 9A to 9C. This was probably due to that the more amount of PDMS led to a relatively larger PDMS domains on the surface and a looser and porous cross-section in the membrane (Figure 9C), which resulted in increased efficient contact areas and reduced mass transfer resistance of the membrane. Therefore, the flux of PDMS-b-PPO membrane was enhanced. This optimum pervaporation performance can be further illustrated from the porous 'non-perforated' structure of the membrane shown in Figure 9C. When the ratio of PDMS:PPO: TDI was 1.5:1:2 (PDMS content is $42.4 \%$ ), the feed concentration was $5 \mathrm{wt} \%$, and the operation temperature was $60^{\circ} \mathrm{C}$, the optimum pervaporation separation behavior was achieved. The separation factor

Table 2. The pervaporation performance of membranes in reference (In the system of ethanol/water)

\begin{tabular}{|c|c|c|c|c|c|}
\hline Membrane & $\begin{array}{c}\text { Ethanol } \\
\text { concentration } \\
{[\mathbf{w t} \%]}\end{array}$ & $\begin{array}{c}\text { Temperature } \\
{\left[{ }^{\circ} \mathrm{C}\right]}\end{array}$ & $\begin{array}{c}\text { Flux } \\
{\left[\mathrm{kg} /\left(\mathrm{m}^{2} \cdot \mathrm{h}\right)\right]}\end{array}$ & $\begin{array}{l}\text { Separation } \\
\text { factor }\end{array}$ & Reference \\
\hline Crosslinked PDMS containing vinyl groups & 16.5 & 40 & 0.085 & 8 & [26] \\
\hline Crosslinked PDMS containing acetoxysilyl groups & 8 & 30 & 0.0251 & 10.8 & [11] \\
\hline PDMS-PS IPN supported on PESF & 10 & 60 & 0.16 & 5.5 & [27] \\
\hline PDMS film treated with octadecyldiethoxymethylsilane & 4.0 & 25 & 0.016 & 16.3 & {$[28]$} \\
\hline PDMS supported on PTFE & 1.5 & 60 & 1.53 & 14 & [29] \\
\hline PDMS supported on CA & 5 & 40 & 1.3 & 8.5 & [12] \\
\hline PTMSP & 6 & 30 & 0.44 & 15.1 & {$[30]$} \\
\hline PTMSP modified with PFA-g-PDMS & 10 & 25 & 0.6 & 20 & [31] \\
\hline Plasma modified with octadecyldiethoxymethylsilane & 4 & 25 & 0.015 & 18 & {$[28]$} \\
\hline PDMS-PI copolymer & 10 & 60 & 0.56 & 10.6 & {$[32]$} \\
\hline PEO-CS blend polymer & 8 & 20 & 0.9 & 4.4 & [33] \\
\hline Silicalite filled PDMS & 5.5 & 22.5 & 0.05 & 16.5 & [34] \\
\hline PDMS-b-PPO asymmetric membrane & 5 & 60 & 3.816 & 8.53 & This work \\
\hline
\end{tabular}


and flux reached 8.53 and $3816.8 \mathrm{~g} /\left(\mathrm{m}^{2} \cdot \mathrm{h}\right)$ for alco$\mathrm{hol} /$ water mixture, 13.54 and $3650.0 \mathrm{~g} /\left(\mathrm{m}^{2} \cdot \mathrm{h}\right)$ for 2propanol /water and 18.18 and $3571.0 \mathrm{~g} /\left(\mathrm{m}^{2} \cdot \mathrm{h}\right)$ for t-butanol/water mixture, respectively.

Table 2 shows the pervaporation performance of other polymeric membranes. As can be shown, our PDMS-b-PPO asymmetric membrane exhibit better flux than that of the reported polymeric membranes while the separation factors maintained on a relatively high level [26-34].

\section{Conclusions}

PDMS-b-PPO membranes were successfully prepared for pervaporation separation of alcohol/water mixtures. The membranes showed a 'non-perforated' structure and high flux in alcohol permselective pervaporation. With the increasing of PDMS content and the decreasing of TDI amounts, the sponge-like structure of PDMS-b-PPO membranes became looser and the PDMS shrinkage domains on surface increased, resulting in the improved separation performance. When the ratio of PDMS: PPO:TDI was 1.5:1:2, the separation factor and flux reached 8.53 and $3816.8 \mathrm{~g} /\left(\mathrm{m}^{2} \cdot \mathrm{h}\right)$ for alcohol/water mixture, 13.54 and $3650.0 \mathrm{~g} /\left(\mathrm{m}^{2} \cdot \mathrm{h}\right)$ for 2-propanol/ water and 18.18 and $3571.0 \mathrm{~g} /\left(\mathrm{m}^{2} \cdot \mathrm{h}\right)$ for t-butanol/ water mixture, respectively. This higher flux for alcohol was attributed to the specific 'non-perforated' structure, which enhanced efficient contact areas and reduced the mass transfer resistance of the membrane. This work provides a new way to design and develop the novel alcohol permselective pervaporation membranes.

\section{Acknowledgements}

This work was financially supported by the National High Technology Research and Development Program of China (NO. 2012AA03A607) and the National Natural Science Foundation of China (NO. 20876003, 21176007 and 21322601).

\section{References}

[1] Kheshgi H. S., Prince R. C., Marland G.: The potential of biomass fuels in the context of global climate change: Focus on transportation fuels. Annual Review of Energy and the Environment, 25, 199-244 (2000). DOI: 10.1146/annurev.energy.25.1.199
[2] Roca C., Olsson L.: Increasing ethanol productivity during xylose fermentation by cell recycling of recombinant Saccharomyces cerevisiae. Applied Microbiology and Biotechnology, 60, 560-563 (2003). DOI: $10.1007 / \mathrm{s} 00253-002-1147-9$

[3] Chum H. L., Overend R. P.: Biomass and renewable fuels. Fuel Processing Technology, 71, 187-195 (2001). DOI: $10.1016 / \mathrm{S} 0378-3820(01) 00146-1$

[4] Çakır T., Arga K. Y., Altıntaş M. M., Ülgen K. O.: Flux analysis of recombinant Saccharomyces cerevisiae YPB-G utilizing starch for optimal ethanol production. Process Biochemistry, 39, 2097-2108 (2004).

DOI: $10.1016 /$ j.procbio.2003.10.010

[5] Shao P., Huang R. Y. M.: Polymeric membrane pervaporation. Journal of Membrane Science, 287, 162-179 (2007).

DOI: $10.1016 /$ j.memsci.2006.10.043

[6] Sae-Khow O., Mitra S.: Pervaporation in chemical analysis. Journal of Chromatography A, 1217, 27362746 (2010). DOI: $10.1016 /$ j.chroma.2009.12.043

[7] Xiangli F. J., Wei W. Chen Y. W., Jin W. Q., Xu N. P.: Optimization of preparation conditions for polydimethylsiloxane (PDMS)/ceramic composite pervaporation membranes using response surface methodology. Journal of Membrane Science, 311, 23-33 (2008). DOI: 10.1016/j.memsci.2007.11.054

[8] Sun H., Lu L., Chen X., Jiang Z.: Pervaporation dehydration of aqueous ethanol solution using H-ZSM-5 filled chitosan membranes. Separation and Purification Technology, 58, 429-436 (2008).

DOI: $10.1016 /$ j.seppur.2007.09.012

[9] Lai J. Y., Li S-H., Lee K-R.: Permselectivities of polysiloxaneimide membrane for aqueous ethanol mixture in pervaporation. Journal of Membrane Science, 93, 273-282 (1994).

DOI: 10.1016/0376-7388(94)00097-2

[10] Li L., Xiao Z., Tan S., Liang P., Zhang Z. B.: Composite PDMS membrane with high flux for the separation of organics from water by pervaporation. Journal of Membrane Science, 243, 177-187 (2004).

DOI: $10.1016 /$ j.memsci.2004.06.015

[11] Ishihara K., Matsui K.: Pervaporation of ethanol-water mixture through composite membranes composed of styrene-fluoroalkyl acrylate graft copolymers and cross-linked polydimethylsiloxane membrane. Journal of Applied Polymer Science, 34, 437-440 (1987). DOI: $10.1002 /$ app.1987.070340135

[12] Ahmed I., Pa N. F. C., Nawawi M. G. M., Rahman W. A. W. A.: Modified polydimethylsiloxane/polystyrene blended IPN pervaporation membrane for ethanol/water separation. Journal of Applied Polymer Science, 122, 2666-2679 (2011). DOI: 10.1002/app.34319 
[13] Nagase Y., Mori S., Matsui K.: Chemical modification of poly(substituted-acetylene). IV. Pervaporation of organic liquid/water mixture through poly(1-phenyl-1propyne)/polydimethylsiloxane graft copolymer membrane. Journal of Applied Polymer Science, 37, 12591267 (1989).

DOI: $10.1002 / a p p .1989 .070370510$

[14] Lunn D. J., Boott C. E., Bass K. E., Shuttleworth T. A., McCreanor N. G., Papadouli S., Manners I.: Controlled thiol-ene functionalization of polyferrocenylsilaneblock-polyvinylsiloxane copolymers. Macromolecular Chemistry and Physics, 214, 2813-2820 (2013).

DOI: $10.1002 /$ macp. 201300520

[15] Dong J., Liu Z., Han N., Wang Q., Xia Y.: Preparation, morphology, and mechanical properties of elastomers based on $\alpha, \omega$-dihydroxy-polydimethylsiloxane/polystyrene blends. Journal of Applied Polymer Science, 92, 3542-3548 (2004).

DOI: 10.1002/app.20394

[16] Kitagawa M., Takegami S., Tokiwa Y.: Free-radical polymerization of a reducing vinyl sugar ester in dimethylformamide and water. Macromolecular Rapid Communications, 19, 155-158 (1998).

DOI: $10.1002 /($ SICI) 1521-3927(19980301)19:3<155:: AID-MARC155>3.0.CO;2-W

[17] Miyata T., Obata S., Uragami T.: Annealing effect of microphase-separated membranes containing poly (dimethylsiloxane) on their permselectivity for aqueous ethanol solutions. Macromolecules, 32, 8465-8475 (1999).

DOI: $10.1021 / \mathrm{ma} 9909612$

[18] Zhao Q., Qian J. W., An Q. F., Zhu Z. H., Zhang P., Bai Y. X.: Studies on pervaporation characteristics of polyacrylonitrile- $b$-poly(ethylene glycol) $-b$-polyacrylonitrile block copolymer membrane for dehydration of aqueous acetone solutions. Journal of Membrane Science, 311, 284-293 (2008).

DOI: $10.1016 /$ j.memsci.2007.12.023

[19] Jha A. K., Chen L., Offeman R. D., Balsara N. P.: Effect of nanoscale morphology on selective ethanol transport through block copolymer membranes. Journal of Membrane Science, 373, 112-120 (2011). DOI: $10.1016 /$ j.memsci.2011.02.043

[20] Jiang Y., Shi H., Cai M., Liang Y., Li B., Zhang H., Song R.: Synthesis and characterization of PS- $b$ PDMS- $b$-PS triblock copolymer. Journal of Applied Polymer Science, 129, 247-252 (2013).

DOI: $10.1002 / a p p .38726$

[21] Miyata T., Obata S., Uragami T.: Morphological effects of microphase separation on the permselectivity for aqueous ethanol solutions of block and graft copolymer membranes containing poly(dimethylsiloxane). Macromolecules, 32, 3712-3720 (1999).

DOI: $10.1021 / \mathrm{ma} 981949 \mathrm{x}$
[22] Miyata T., Takagi T., Uragami T.: Microphase separation in graft copolymer membranes with pendant oligodimethylsiloxanes and their permselectivity for aqueous ethanol solutions. Macromolecules, 29, 77877794 (1996). DOI: $10.1021 / \mathrm{ma960663 \textrm {u }}$

[23] Miyata T., Higuchi J-I., Okuno H., Uragami T.: Preparation of polydimethylsiloxane/polystyrene interpenetrating polymer network membranes and permeation of aqueous ethanol solutions through the membranes by pervaporation. Journal of Applied Polymer Science, 61, 1315-1324 (1996).

DOI: 10.1002/(SICI)1097-4628(19960822)61:8<1315:: AID-APP11>3.0.CO;2-Y

[24] Schauer J., Sysel P., Maroušk V., Pientka Z., Pokorný J., Bleha M.: Pervaporation and gas separation membranes made from polyimide/polydimethylsiloxane block copolymer. Journal of Applied Polymer Science, 61, 1333-1337 (1996).

DOI: 10.1002/(SICI)1097-4628(19960822)61:8<1333:: AID-APP13>3.0.CO;2-\#

[25] Liu W., Ji S-L., Guo H-X., Gao J., Qin Z-P.: In situ cross-linked-PDMS/BPPO membrane for the recovery of butanol by pervaporation. Journal of Applied Polymer Science, 131, 4004/1-4004/9 (2014).

DOI: $10.1002 / a p p .40004$

[26] Takegami S., Yamada H., Tsujii S.: Pervaporation of ethanol/water mixtures using novel hydrophobic membranes containing polydimethylsiloxane. Journal of Membrane Science, 75, 93-105 (1992).

DOI: 10.1016/0376-7388(92)80009-9

[27] Liang L., Ruckenstein E.: Pervaporation of ethanolwater mixtures through polydimethylsiloxane-polystyrene interpenetrating polymer network supported membranes. Journal of Membrane Science, 114, $227-$ 234 (1996).

DOI: 10.1016/0376-7388(95)00319-3

[28] Kashiwagi T., Okabe K., Okita K.: Separation of ethanol from ethanol/water mixtures by plasma-polymerized membranes from silicone compounds. Journal of Membrane Science, 36, 353-362 (1988).

DOI: $10.1016 / 0376-7388(88) 80028-0$

[29] Mori Y., Inaba T.: Ethanol production from starch in a pervaporation membrane bioreactor using Clostridium thermohydrosulfuricum. Biotechnology and Bioengineering, 36, 849-853 (1990). DOI: 10.1002/bit.260360815

[30] Volkov V. V., Fadeev A. G., Khotimsky V. S., Litvinova E. G., Selinskaya Y. A., McMillan J. D., Kelley S. S.: Effects of synthesis conditions on the pervaporation properties of poly[1-(trimethylsilyl)-1-propyne] useful for membrane bioreactors. Journal of Applied Polymer Science, 91, 2271-2277 (2004). DOI: 10.1002/app.13358 
[31] Uragami T., Doi T., Miyata T.: Control of permselectivity with surface modifications of poly[1-(trimethylsilyl)-1-propyne] membranes. International Journal of Adhesion and Adhesives, 19, 405-409 (1999).

DOI: $10.1016 / \mathrm{S} 0143-7496(98) 00064-5$

[32] Krea M., Roizard D., Moulai-Mostefa N., Sacco D.: New copolyimide membranes with high siloxane content designed to remove polar organics from water by pervaporation. Journal of Membrane Science, 241, 55-64 (2004).

DOI: $10.1016 /$ j.memsci.2004.03.040
[33] Wang X-P., Shen Z-Q., Zhang F-Y., Zhang Y-F.: Preferential separation of ethanol from aqueous solution through hydrophilic polymer membranes. Journal of Applied Polymer Science, 73, 1145-1151 (1999). DOI: 10.1002/(SICI)1097-4628(19990815)73:7<1145:: AID-APP6>3.0.CO;2-B

[34] te Hennepe H. J. C., Bargeman D., Mulder M. H. V., Smolders C. A.: Zeolite-filled silicone rubber membranes: Part 1. Membrane preparation and pervaporation results. Journal of Membrane Science, 35, 39-55 (1987).

DOI: $\underline{10.1016 / \mathrm{S} 0376-7388(00) 80921-7}$ 